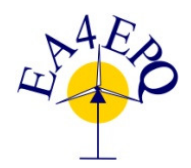

\title{
Sunwater and beyond
}

\section{Buschert \\ South Westphalia University of Applied Sciences, Campus Soest, Lübecker Ring 2, 59494 Soest, Germany Buschert.Daniel@googlemail.com}

\begin{abstract}
Due to the increasing water shortages not only in sunny countries, but also in a lot of other states, the demand on freshwater will increase worldwide in the near future. Good examples are the newly industrializing countries. The freshwater demand increases with the wealth of the inhabitants. The so called virtual water must also be taken into account. This is water which is needed to produce products, but it is not included in the final commodity.

During the Sunwater project a demonstration plant was planned, modeled, simulated and installed which uses renewable energies to desalinate freshwater with a very high quality. Solar thermal energy was used to convert saltwater from the Red Sea into freshwater. For this purpose an innovative evaporation desalination unit from Germany was used. The complete project was a feasibility study with partners from Germany, Egypt and UK.

In this paper a few modifications and additional application possibilities are presented to use this demonstration plant. This includes e. g. other prospects for the heat storage tanks and the usage of the water desalination unit itself.
\end{abstract}

Keywords - Environmentally friendly energy production, Water desalination and sustainable water management, optimization and enhancement of the system, future prospects of the Sunwater project

\section{Starting position}

Freshwater is a very important product in our time. At the earth only a fixed amount on freshwater is available. An overview of the earth's total water amount can be found in Fig. 1. $97.5 \%$ is saltwater and therefore it cannot directly be used for the daily life. It must be converted with desalination systems into usable freshwater. This generation has a very high energy consumption. At the moment there exists different kind of desalination systems. They are grouped in membrane and thermal desalination systems. Membrane desalination systems are for example reverse osmosis or electrodialysis systems and thermal desalination systems are multi-stage flash, multi effect or evaporation desalination systems. Other systems are experimental and work with electric fields. Furthermore it should also be possible to desalinate saltwater with magnetic fields. This can for example be combined with electrical fields and superconducting solenoid coils. In experimental systems salt and freshwater is separated with the Lorentz force.

As it was mentioned before $97.5 \%$ is saltwater and therefore it is not directly usable. As can be seen in Fig. 1 the missing $2.5 \%$ are freshwater, but just a very low amount is directly usable. The most is stored in ice caps and glaciers. These are $70 \%$ of the complete freshwater. The remaining $30 \%$ are liquid, but $97 \%$ of the remaining liquid water is

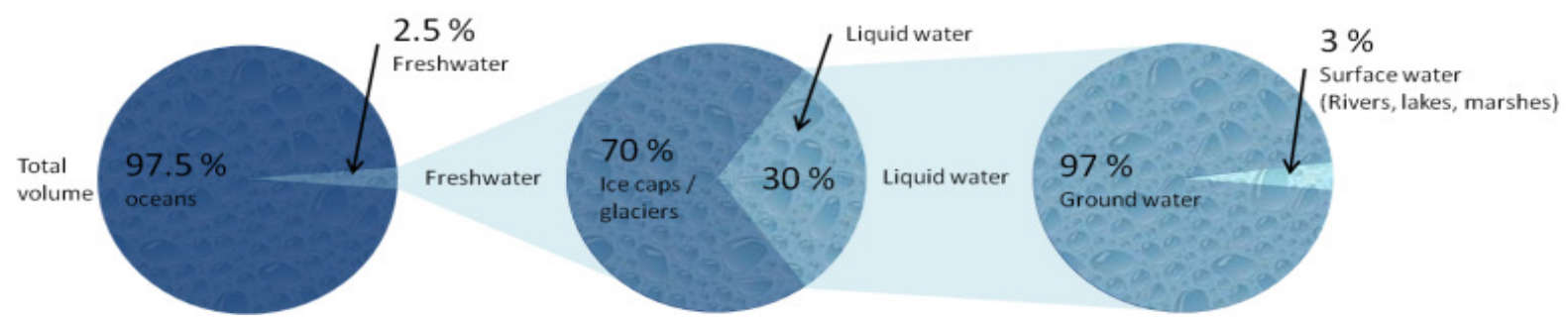

Fig. 1: Water distribution on our earth. 
stored as groundwater and just $3 \%$ is surface water. It is stored in rivers, lakes or marshes. Unfortunately it is also unequal balanced not only on the world, but also in the country itself. A good example is Egypt. The most freshwater is in the Nile, but in the urban hinterland no freshwater can easily be found. It must be transported to consumer by pipelines or by trucks. In the tourist areas, e. g. in Hurghada or Safaga at the Red Sea, almost the whole freshwater is generated with desalination. At the moment fossil fuels are used to generate the needed energy for the desalination systems. In other countries like in Norway the total renewable water resources per inhabitant are $84178 \mathrm{~m}^{3}$. In comparison to Egypt it is just $786 \mathrm{~m}^{3}$. In Egypt the water withdrawals per inhabitant are $937 \mathrm{~m}^{3}$ and in Norway just $483 \mathrm{~m}^{3}$. In Egypt the amount of the renewable water resources are lower than the water withdrawals. In Saudi-Arabia the situation is more difficult. The renewable water resources per inhabitant are just $97 \mathrm{~m}^{3}$ compared to $959 \mathrm{~m}^{3}$ which is the water withdrawals. In a long-term view the difference must be covered with desalination otherwise these and other countries could get in trouble. Due to the shortfalls of water there is the fear that there could be a lot of water wars in the world in the near future. [5] Not only the direct use of water is important for the freshwater calculation, but also the so called virtual water must be considered during the life cycle. Virtual water is the water, which is used for the production of the product and which is not included in the final product. It varies extremely from product to product. For one 0.33 I Coca Cola can $70 \mathrm{l}$ of virtual water is needed. For $1 \mathrm{~kg}$ corn 1400 I of freshwater is needed, 500 pages of DINA4 paper needs $5000 \mathrm{I}$ and for $1 \mathrm{~kg}$ beef $5000 \mathrm{I}$ 20000 I of freshwater is necessary. Further comparisons can be found in Fig. 2. As can be seen, the virtual water demand is much higher than the real water demand, but for the production of the commodity it is necessary. The demand could perhaps be somewhat reduced, but freshwater is always needed for the production.

A German for example uses less than $130 \mathrm{l} / \mathrm{d}$ freshwater, but the virtual demand on freshwater, which is also called the virtual footprint, is more than $4000 \mathrm{l} / \mathrm{d}$. Actual $50 \%$ of the virtual water amount is imported, because the products are produced abroad and then transported to Germany.

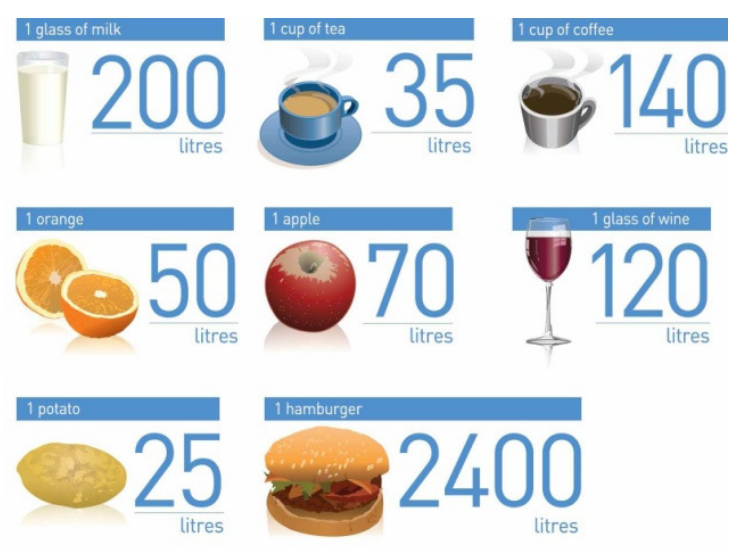

Fig. 2: Virtual water demand of different products [6].

\section{Sunwater project}

The Sunwater project [2] was an international project between Germany, Egypt and UK. This project was funded by the RDI in Egypt and it was initialized by this author. The first idea of the project was shown in [1] and in [2]. First results of this future oriented project were shown in [3] and [4]. The idea of the Sunwater project was to plan, model, simulate and install a solar desalination system which works with renewable energies. In this case an evaporation desalination unit from Germany was chosen which was operated with solar thermal energy. The whole system was installed in Hurghada in Egypt. This place was chosen, because of the world highest solar radiation which is sometimes higher than $1000 \mathrm{~W} / \mathrm{m}^{2}$. Furthermore the other weather conditions are also excellent, because of almost no rain and clouds during the whole year.

Before the system was built a system model was created in Simulink. This included a model of the solar thermal part of the system with e. g. the solar thermal roof, the heat storage tanks and the heat pump. For this part of the system the CarnotToolbox [7] was used and had to be modified slightly, because it was built for a different application. The model of the water desalination unit was also implemented in Simulink. This model also consisted of different components like e. g. heat exchangers, a flow diverter and a flow mixer. This part of the system was modeled on a mathematical foundation.

An overview of the whole system can be found in Fig. 3. The system consists of a solar thermal roof which is installed to generate thermal heat. Furthermore two heat storage tanks were planned 


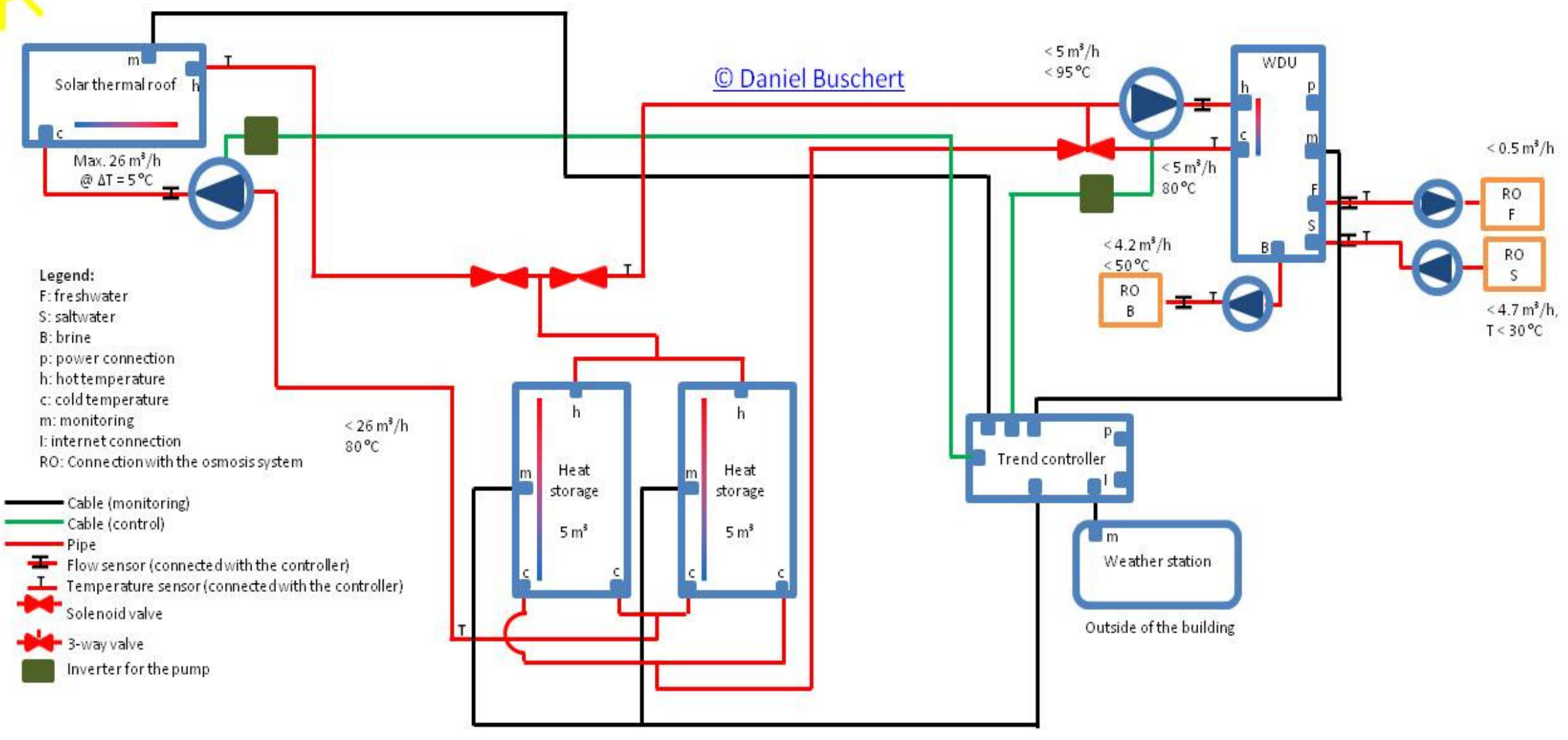

Fig. 3: System model of the Sunwater project, which was planned in Germany and installed in Egypt. 
to buffer and store the produced hot water. Each size was $5 \mathrm{~m}^{3}$. With this hot water the water desalination unit was operated to convert the saltwater from the Red Sea into freshwater. Additionally two control systems were installed to monitor and adjust the solar thermal system and the water desalination unit. It was also possible to control and adjust the system via the internet. Both controllers used were easily accessible via a VPN. They were connected to a GSM router and with this router the needed internet connection was established.

The solar thermal system was connected to an existing reverse osmosis system. This had the advantage that the intake of the saltwater and the disposal of the brine and the freshwater from the RO system could be used. This was a financial benefit. Furthermore a weather station was installed to measure the actual weather conditions at the building site. At the roof, close to the vacuum tube collectors, there were e.g. be installed an ultrasonic wind sensor, a temperature sensor and a solar radiation sensor. The volume flows of the two pumps in the solar thermal system were controllable with an inverter. The pump for the solar thermal roof was adjusted in that way, that the output temperature is between $90^{\circ} \mathrm{C}$ and $95^{\circ} \mathrm{C}$, which is the working temperature of the water desalination unit. The second pump and the 3-way-valve were installed to adjust the energy delivery to the water desalination unit. It was possible to control the volume flow and the temperature of the heat source. There can also be found different temperature sensors, volume flow sensors and two solenoid valves in the system. The two solenoid valves were planned to reduce the thermal flows during the night and on cloudy days. During this time hot water from the heat storage tanks can flow in the pipes to the solar thermal roof. There it will be cooled down and the cold water flows back to the heat storage tanks. Due to this close circuit a lot of stored energy is squandered during the night. If enough thermal energy was available in the system, it was transferred to the water desalination unit by activating the heat delivery pump. The mentioned control strategy for the solar thermal part of the system was included into the controller from Trend [8]. It was planned, programmed and adjusted at the University in Soest.
As it was mentioned before the system was installed and tested in Hurghada. The solar thermal roof produces enough thermal heat to operate the water desalination unit and to produce usable freshwater. During this feasibility studies it was seen that the system is still optimizable. The storage of the heat is very difficult. The heat storage tanks were too small to store enough thermal heat to operate the water desalination unit for hours after sunset or on cloudy days. During the installation the solenoid valves were not installed correctly in the system and therefore hot water circulates in the system and was cooled down during the night. This was a reason why a lot of energy was lost during the night. The temperature in the system drops for several degrees. These energy losses must be gathered at the next day. As can be seen in Fig. 4 the volume flow varies during the day. In the morning and the evening the volume flows from the thermal roof is below the constant demand of the water desalination unit. Therefore hot water in the morning must be stored to raise the efficiency. This can be used later to operate the water desalination unit. This is before the breakeven point, because the stored hot water in the heat storage tanks and the produced volume flow from the solar thermal roof are enough to operate the water desalination unit. Later during the day more hot water is theoretically produced than used by the water desalination unit. The surplus water can be stored in the heat storage tanks for a later usage. This water can be used in the evening, when the volume flow from the solar thermal roof is below the demand or during the time when clouds are on

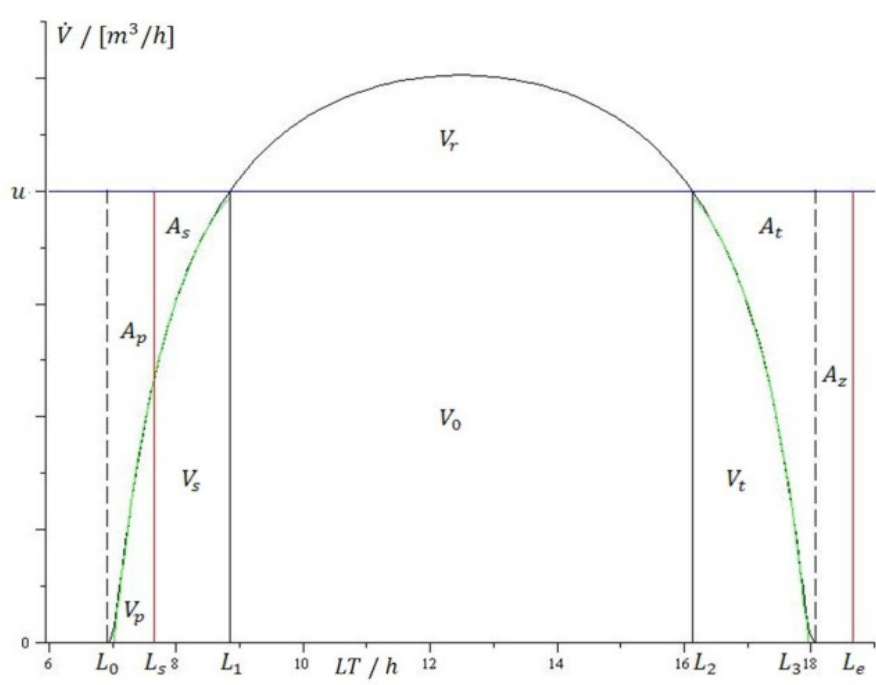

Fig. 4: Variation of the volume flow during the day. 
the sky. Due to the stored energy the operation time of the water desalination can be extended and therefore the efficiency of the whole system can be raised.

During the project life time it was discovered that the temperature control of the volume flow from the solar thermal roof is very difficult. It must be optimized in later realizations. It happened from time to time that the temperature rises surprisingly to a temperature higher than the needed $90{ }^{\circ} \mathrm{C}-95^{\circ} \mathrm{C}$. This was a big problem, because the maximum working temperature of the volume flow sensors was slightly above $100^{\circ} \mathrm{C}$ and the maximum working temperature of the water desalination unit was just $95^{\circ} \mathrm{C}$. A damage of the components is possible. Therefore an optimization is still needed. For a better control of the temperature more temperature sensors are needed to provide a better insight into the whole system. With more data a better control strategy is still possible. This must be implemented in later realizations, because the system was dismantled in the past.

\section{Sunwater and beyond}

During this project it was seen that it is possible to operate a water desalination unit with solar thermal energy, but the energy production with a solar thermal roof is very difficult. Furthermore the storage of the thermal heat is also very challenging. During the day only a few hours can be used to generate enough thermal energy for a $24 \mathrm{~h}$ operation of the water desalination unit. Either the solar radiation must be very high to produce enough thermal heat with a relative small solar thermal field or the solar thermal field must be very large, if the solar radiation is very low. With better vacuum tube collectors the volume flow temperature can be raised to higher temperatures like $150^{\circ} \mathrm{C}$ or more. In this case the components of the solar thermal part of the system must be exchanged in that way, that such high operation temperatures can be processed. This affects the whole system. It must be operated with overpressure and the most components must be exchanged. This problem should be solvable. It is more desirable to operate the water desalination unit not only with solar thermal energy, but also with another renewable thermal heat sources. This could for example be waste heat from a thermal power station which is operated with renewable non-fossil fuels. This power plant can deliver the needed primary energy for the basic load and for a continuous operation. The solar energy is only used in the primary processing time and peak times.

Another problem was the storage of the process water. In the Sunwater project only standard heat storage tanks were used to store and buffer it. Due to the standard pressure operation the maximum storage temperature was slightly higher than the operation temperature of the water desalination unit. And therefore the usable energy density in the heat storage tanks was very low. In later realizations it is appreciated to use other heat storage tanks. It could e. g. be used heat storage tanks which are made of phase changing materials (PCM). The advantage is that a lot of energy can be stored in the phase change of the material. During the phase change between two different phases more energy can be stored compared to an exclusive temperature rise in a fluid or in a solid. For example, $1 \mathrm{~kg}$ ice at $0{ }^{\circ} \mathrm{C}$ needs $333 \mathrm{~kJ}$ for melting. If the same energy amount is added to the liquid after melting, it increases its temperature to $80^{\circ} \mathrm{C}$. The energy, which is needed for melting, is called latent heat and it is characteristic for all phase changes [5]. Additionally the phase changes can be repeated several times without any problem. For the heat storage for the Sunwater project the phase change from solid to liquid must be in the range between $80^{\circ} \mathrm{C}$ and $110^{\circ} \mathrm{C}$. Therefore ice and liquid water cannot be used, but there is the possibility to use sugar alcohols or paraffins, which have a phase change in the right temperature range. The enthalpy of fusion is in the range between $200 \mathrm{~kJ} / \mathrm{l}$ and $400{ }^{\circ} \mathrm{kJ} / \mathrm{l}$. For temperatures up to $200{ }^{\circ} \mathrm{C}$ nitrates or hydroxides can be used, which have a much higher enthalpy of fusion. It is in the range between $200 \mathrm{~kJ} / \mathrm{l}$ and $700 \mathrm{~kJ} / \mathrm{l}$. The volume flows with higher temperatures must be mixed up with colder water to get volume flows in the right working range of the water desalination unit. The colder water e. g. can come from the back flow of the water desalination unit. For this a 3-way valve can be used which was already installed in the demonstration plant. For higher temperatures the control strategies of the whole system must be improved. This combination has also the advantage that the operation time of the system can be 
extended, because more energy can be stored in the system

Another possibility is to use a solar pond as a heat storage tank and additionally as an energy collector. This special storage technology is based on the density, temperature and concentration gradient between the bottom and the surface of the reservoir. A rough overview of a solar pond can be found in Fig. 5. It is also observable in natural salt lakes like in the Solar Lake close to the Red Sea in Egypt. At the top of the pond the temperature is nearly ambient temperature, but in the depth the temperature can rise up to $90{ }^{\circ} \mathrm{C}$ and higher. This heat source and storage can be tapped as a heat source for the desalination unit. Furthermore it should also be possible to store the produced heat from the solar roof inside the solar pond for later usage. The idea behind is that in the solar pond different water layers with different salinities are present at the same time. At the bottom is the layer with the highest salinity and at the top there is a layer with the lowest salinity. Between both layers a salinity gradient can be established. Without any outer impact the solar pond is stable, because the water with the highest salinity has the highest density and therefore this layer is located at the bottom of the solar pond. At the top is the water with the lowest salinity and therefore it has the lowest density. The solar radiation enters the pond from the top and then it is absorbed at a light absorbing surface at the bottom of the solar pond, where the solar radiation is converted into heat. Due to the different salinities the heat is captured at the bottom and will not be released to the environment. The temperature increases continuously. Warmer water has a lower density compared to colder water. Therefore it should normally climb to the surface and release the stored heat. It cools down and should descend to the ground. Due to the different salinities the hot water cannot climb to the surface and stays at the ground and therefore the temperature difference at the surface between the liquid and the air is relatively low and thus the energy losses are reduced. Herewith a natural heat insulation is established. The problem is that for a stable temperature layering and a good heat insulation no turbulences, water waves or flows are desirable inside the pond, which destroy the different layers in the pond.

Another possibility of the usage of the water desalination unit is to produce common salt. The salt in the saltwater can be concentrated to very high values in a closed cycle and then it is very easy to extract common salt. It can for example be cascaded with existing desalination systems, because the maximum processible salinity concentration is higher than e.g. in RO systems. The remaining brine, this is the water with the higher salinity, can be stored outside the building in basins and then the remaining water can evaporate. The common salt must only be skimmed. The worst desalination system for the salt production is the electrodialysis, followed by the reverse osmosis desalination system. The highest salt concentration can be processed with

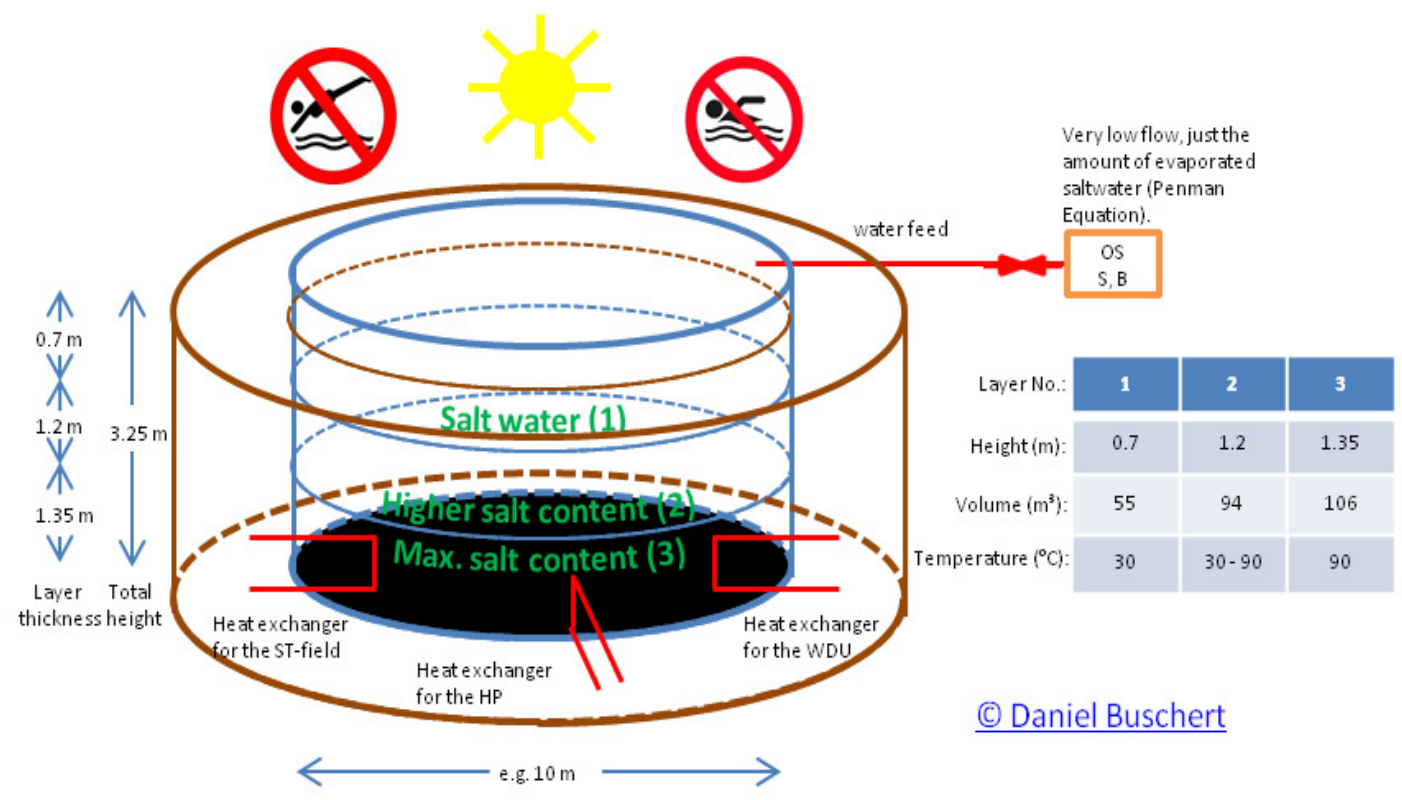

Fig. 5: Solar pond 
thermal desalination systems and especially with the evaporation desalination system.

Another possibility for the water desalination unit is to concentrate particulate matters and wastes in waste water. The carrier of the particles is reduced and then less waste water must be depolluted. This has a financial benefit for companies.

In both cases, the salt production and the waste water treatment, usable freshwater is produced which can be used for important applications like freshwater supply or to crop plants.

\section{Conclusion}

As it could be seen in the Sunwater project, it is possible to convert saltwater into freshwater with renewable energies. The first steps were met, but a lot of different optimizations are still possible. The storage of the thermal energy must be optimized, the losses during the night must be reduced and the whole system must be scaled to larger dimensions. The system can e. g. be extended with other renewable heat sources. This could be a combined heat and power plant which works with renewable resources.

Additionally it could also be possible to use brine to generate common salt. The salt in the brine must be concentrated to its maximum which can still be handled with the desalination unit. The maximum salt concentration depends on the used desalination system.

Furthermore it is also possible to concentrate impurities inside the raw water. Of course it depends slightly on the pollutions inside the water. Now it is easier and cheaper to depollute the remaining fluids.

The usage of renewable energies is future proof and makes it easy to install the systems in developing countries. In sun-rich countries (thermal) energy can be generated directly close to consumers and therefore the transport losses are reduced. In the near future new solar thermal modules could be invented which have a better efficiency.

During the project life-time it was also discussed, that it is possible to cascade the evaporation desalination units with existing desalination systems. The evaporation desalination unit can process higher salinities than e. g. RO-systems and therefore the efficiencies of other systems can be increased.

\section{Acknowledgement}

Now I want to thank all people who supported me in the last years. This includes all members of the Sunwater project in Germany, Egypt and UK.

\section{References}

[1] D. Buschert, B. Bitzer, "Optimization of energy parks with biomass plants and water desalination", UPEC 2008 conference, Padua, Italy, September 2008

[2] D. Buschert, B. Bitzer, "Concept for Optimization and Simulation of Renewable Energy Parks with Desalination”, ICREPQ’09 conference, Valencia, Spain, April 2009

[3] D. Buschert, B. Bitzer, "Modeling a solar desalination", ICREPQ'10 conference, Granada, Spain, March 2010

[4] D. Buschert, B. Bitzer, "Water desalination with evaporation from environmental friendly waste heat source", UPEC 2011 conference, Germany, South Westphalia University, Campus Soest, September 2011

[5] D. Buschert, "Sunwater-Project - An innovative Water Desalination System operated with Solar Thermal Energy", PhD Thesis, University of Bolton, UK, 2014

[6] www.sciencemediacentre.co.nz

[7] Carnot Toolbox, Solar-Institut Jülich, Aachen, Germany

[8] www.trendcontrols.com 